\title{
Odor-based double-alternation responding and retention as a function of naloxone injection
}

\author{
STEPHEN F. DAVIS, MICHAEL M. DUDECK, and MELANIE S. WEAVER \\ Emporia State University, Emporia, Kansas 66801
}

\begin{abstract}
A two-phase experiment designed to investigate the effects of naloxone injection upon odorbased double-alternation performance is reported. Two groups of rat subjects received a daily eight-trial sequence of reward/nonreward in a straight runway during both phases of the experiment. Subjects in Group $\mathbf{N}$ received an injection of naloxone on each of the last 2 days of Phase 1 . Subjects in Group $S$ received an injection of isotonic saline on these 2 days. Phase 1 performance was not significantly influenced by the naloxone treatment. However, Group $\mathbf{N}$ displayed significantly superior retention of double-alternation patterning on Day 1 of Phase 2, begun 2 weeks after the completion of Phase 1.
\end{abstract}

Hughes (1975) reported the isolation of an endogenous opiate-like peptide. Subsequent research (e.g., Cannon, Liebeskind, \& Frenk, 1978; Sherman \& Liebeskind, 1979; Terenius, 1978) has indicated that these compounds, the endorphins, are important in the detection of and reaction to noxious stimulation. More specifically, their action appears to be that of inhibiting pain. If the endorphins act to inhibit pain, then administration of an opiate antagonist (e.g., naloxone) should result in greater sensitivity and/or a more pronounced reaction to the application of noxious or aversive stimulation. In support of this action of naloxone, Fanselow, Sigmundi, and Bolles (1980) have shown that rat subjects pretreated with naloxone displayed enhanced shockelicited aggression responding when compared with saline-injected control animals. Similarly, Fanselow and Bolles (1979) have shown that the display of freezing behavior following the application of electric shock was also enhanced by naloxone injection. To explain such findings, Fanselow and Bolles (1979) have postulated that the naloxone blocked the endorphin system. Hence, the release of these natural opiates was precluded and the reaction to the aversive stimulation was enhanced or the event perceived as more painful. Izquierdo (1979) has also reported that naloxone injection enhanced the retention of a standard shuttle-avoidance task. This finding suggests that the endorphins may also act as inhibitors of memory consolidation.

A second, seemingly unrelated, line of research has concerned itself with the olfactory control of animal maze learning. For example, it has been clearly demonstrated (e.g., Davis, Prytula, Noble, \& Mollenhour, 1976; Davis, Whiteside, Bramlett, \& Petersen, in press; Ludvigson \& Sytsma, 1967; Prytula \& Davis, 1976; Seago, Ludvigson, \& Remley, 1970) that rats are capable

This research was supported, in part, by a grant from the Research and Creativity Committee of Emporia State University to the first author. of learning an eight-trial double-alternation pattern of reward (R)/nonreward (N) (i.e., RRNNRRNN) under odor-maximizing conditions, but not under odorminimizing conditions. Such studies have typically been conducted in the straight-runway apparatus, with learning being defined as the achievement of appropriate patterned responding (i.e., fast to reward, slow to nonreward). These results have prompted the conclusion that unique odors are exuded on rewarded and nonrewarded events, respectively. Electrophysiological recordings from single cells in the medial olfactory bulb of the rat (Voorhees, 1980) have supported this contention.

If one is willing to entertain the proposition that encountering the odor of nonreward represents an aversive event, then an interaction between these two lines of research might be postulated. (A 1973 report by Mellgren, Fouts, and Martin has presented data suggesting that the odor of nonreward may be aversive.) Assuming the odor of nonreward to be aversive, then, given the Fanselow and Bolles (1979), Fanselow et al. (1980), and Izquierdo (1979) data, one might predict that naloxone injections would have the effect of enhancing performance and/or retention of odor-based double-alternation responding. It might also be predicted that such effects would be most clearly seen via changes in $\mathrm{N}$-trial performance. The present study sought to investigate these predictions.

\section{METHOD}

\section{Subjects}

Fourteen 90-day-old male Holtzman rats, individually caged with water freely available, served as subjects. One week prior to the start of pretraining, all subjects were placed on food deprivation and maintained at $85 \%$ of their free-feeding body weights.

\section{Apparatus}

A single straight runway (more fully described in Davis et al., in press) served as the experimental apparatus. A microswitch, in conjunction with a series of photorelays and electronic timers 
(Lafayette Model 54030), allowed the recording of start, run, and goal latencies on all trials. The entire apparatus was covered with a thin sheet of transparent plastic to prevent the dissipation of odors.

\section{Procedure}

Two equal-sized groups ( $n=7), S$ and $N$, were randomly formed at the beginning of a 4-day pretraining period that immediately preceded the start of experimental testing. On Pretraining Days 1 and 2, all animals were handled and tamed for $1 \mathrm{~min}$ each. A 5 -min exploration period in the unbaited runway was administered to all subjects on Days 3 and 4 of pretraining. Home-cage habituation to the $45 \mathrm{mg}$ Noyes reward pellets to be used during experimental testing occurred for all subjects on all days of pretraining.

A permanent number (1-7) was randomly assigned to each subject in Group $S$ and Group $N$ at the beginning of experimental testing. Subjects within each group were run in this order on all days of the experiment.

Experimental testing was divided into two phases. During both phases, all subjects received eight trials, administered in a double-alternation sequence (RRNNRRNN), per day. A rewarded event always consisted of $1245-\mathrm{mg}$ pellets, and a nonrewarded event was always $15 \mathrm{sec}$ confinement in an empty goalbox.

Phase 1 lasted 12 days (96 trials). On each of the last 2 days of this phase, each subject in Group $\mathrm{N}$ was administered a $1-\mathrm{mg} / \mathrm{kg}$ intraperitoneal injection of naloxone immediately prior to runway training. On these days, each subject in Group S was administered a $1-\mathrm{mg} / \mathrm{kg}$ intraperitoneal injection of $.9 \%$ isotonic saline immediately prior to runway training. Otherwise, the two groups were treated identically.

Phase 2 was begun exactly 2 weeks after the completion of Phase 1 and lasted 3 days (24 trials). During the 2 -week interim between Phase 1 and Phase 2, all subjects were maintained on food deprivation but received no additional training or handling.

On all days, all subjects within a group received Trial 1 before Trial 2 was administered, and so forth. At the completion of each trial, the apparatus was swabbed with a damp sponge and aired for $5 \mathrm{~min}$. Thus, Subject 1 in each group was always tested in a clean, odor-free runway. All eight daily trials were administered to a group before testing with the other group was begun. The order for running groups was rotated daily.

\section{RESULTS}

For purposes of statistical analysis and graphical presentation, the daily latencies were treated in the following manner. All latencies were reciprocated and multiplied by the appropriate constant to yield speed scores in meters per second. The speed scores for the eight-trial double-alternation sequence were then combined thusly: The first two trials were averaged to yield an $R_{1}$ composite score, the next two trials were averaged to yield an $\mathrm{N}_{1}$ composite score, and so forth. Hence, the eight daily trials were reduced to four representative scores. It should also be noted that since Subject 1 in each group was tested in a clean, swabbed runway and served as an odor donor, the data for these animals were not included in graphs or statistical analyses. Visual inspection of the speeds of these two animals indicated that they displayed nondifferential responding on all days of the experiment.

Mean goal speeds for Groups $\mathrm{S}$ and $\mathrm{N}$ for both phases of the experiment are shown in Figure 1. As can be seen

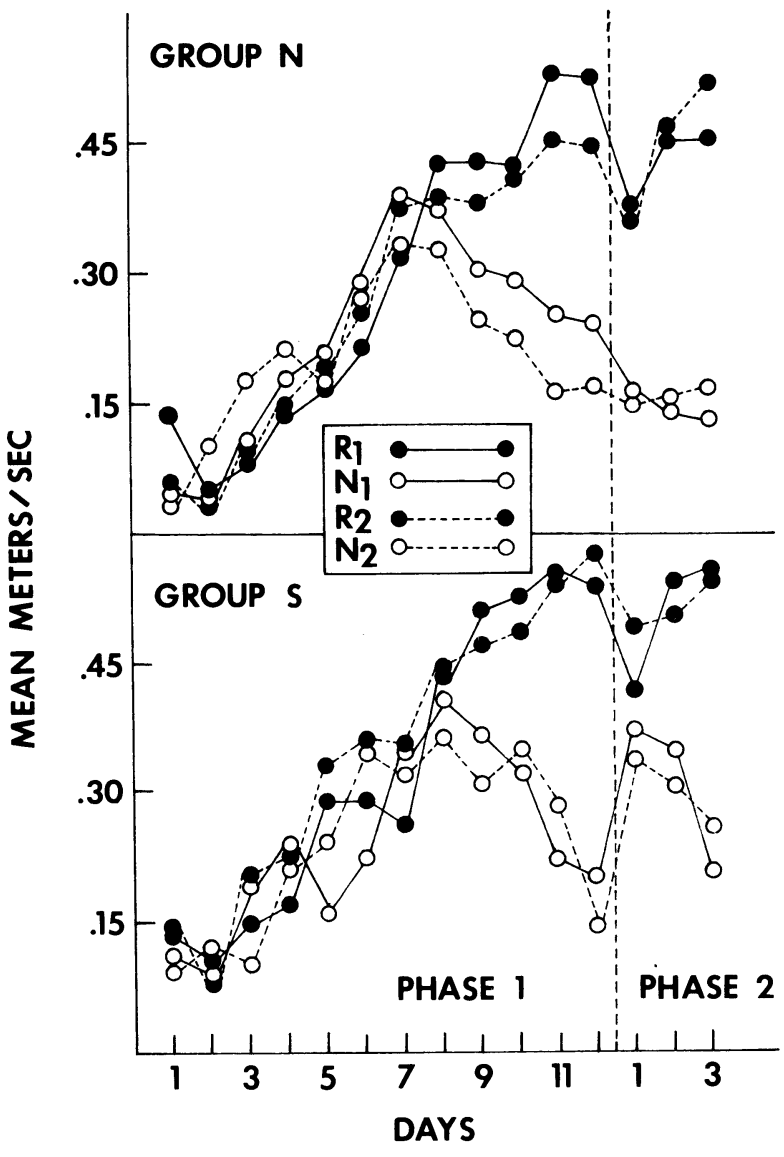

Figure 1. Mean goal speeds (in meters per second) for Group N (naloxone injected) and Group S (saline injected) for Phases 1 and 2.

from this figure, both groups appeared to have established appropriate double-alternation patterning by the end of Phase 1. Other than a slight elevation in $R_{1}$ speeds, the performance of Group $\mathrm{N}$ did not appear to be influenced by the naloxone treatment on the last 2 days of Phase 1 . The disruption in the patterned responding of Group $S$ and the lack of such disruption on the part of Group $\mathrm{N}$ on Day 1 of Phase 2 suggest that the naloxone treatment may have influenced the retention of double-alternation patterning.

Analysis of variance incorporating groups (S vs. N), days, and $\mathrm{R}$ vs. $\mathrm{N}$ factors was performed on the start-, run-, and goal-measure speeds for Days 9-12 of Phase 1 (the point at which appropriate patterning appeared to have been established) and Days 1-3 of Phase 2. Startand run-measure analyses failed to yield significant effects for both Phases 1 and 2 . A significant $\mathrm{R}$ vs. $\mathrm{N}$ effect $[F(1,10)=13.76, p<.01]$ was shown in the Phase 1 goal-measure analysis. The Phase 2 goal-measure analysis yielded significance for the $R$ vs. $N[F(1,10)=$ $7.55, \mathrm{p}<.05]$ and Groups by Days by R-N interaction $[F(2,20)=4.43, p<.05]$ effects. The Newman-Keuls procedure was used to make specific comparisons and 
indicated that significant $(\mathrm{p}<.01) \mathrm{R}$ vs. $\mathrm{N}$ differences were shown by Group $\mathrm{N}$ on all days of Phase 2 . Significant $(p<.01) R$ vs. $N$ differences were shown by Group S only on Days 2 and 3 of Phase 2. Thus, the statistical results corroborate the graphical impression created by Figure 1.

\section{DISCUSSION}

Three salient points are suggested by the results of this study. First, it does not appear that the injection of naloxone results in any major change in the performance of odor-based double-alternation responding that has already been established. On the other hand, naloxone treatment does appear to result in better retention of such responding, at least over a 2-week period of time. While the first result does not seem to be in complete agreement with the Fanselow and Bolles (1979) and Fanselow et al. (1980) data, it may suggest that the type of aversive stimulus employed in naloxone studies is an important variable. That superior retention for double-alternation patterning was shown by Group $\mathrm{N}$ is certainly supportive of the findings reported by Izquierdo (1979). As originally suggested, the major retention effect of the naloxone appeared to be on $\mathrm{N}$-trial (odor of nonreward) performance. As Figure 1 indicated, both Groups $\mathrm{S}$ and $\mathrm{N}$ showed a drop in R-trial speeds on Day 1 of Phase 1. However, the sharp increase in N-trial speeds shown by Group S on this day is to be contrasted with the complete lack of such changes by Group N. Finally, it should be noted that even though Group $\mathrm{S}$ did not display significant patterning behavior on the 1st day of Phase 2, such responding was strongly reestablished by Day 2. As retention of odor-based responding has apparently not been directly addressed in the literature, this finding adds to the growing body of data implicating odor cues as potentially important determinants of maze performance of the rat.

\section{REFERENCES}

Cannon, J. T., Liebeskind, J. C., \& Frenk, H. Neural and neurochemical mechanisms of pain inhibition. In R. A. Sternbach (Ed.), The psychology of pain. New York: Raven Press, 1978.
Davis, S. F., Prytula, R. E., Noble, M. J., \& Mollenhour, M. N. Motivational specificity of the signal value of odor cues. Animal Learning \& Behavior, 1976, 4, 407-410.

Davis, S. F., Whiteside, D. A., Bramlett, J. A., \& Petersen, S. H. Odor production and utilization under conditions of nonreward and small reward. Learning and Motivation, in press.

Fanselow, M. S., \& Bolles, R. C. Naloxone and shock-elicited freezing in the rat. Journal of Comparative and Physiological Psychology, 1979, 93, 736-744.

Fanselow, M. S., Sigmundi, R. A., \& Bolles, R. C. Naloxone pretreatment enhances shock-elicited aggression. Physiological Psychology, 1980, 8, 369-371.

Hughes, J. Isolation of an endogenous compound from the brain with pharmacological properties similar to morphine. Brain Research, 1975, 88, 295-308.

IzQUIERDO, I. Effect of naloxone and morphine on various forms of memory in the rat: Possible role of endogenous opiate mechanisms in memory consolidation. Psychopharmacology, 1979, 66, 199-203.

Ludvigson, H. W., \& Sytsma, D. The sweet smell of success: Apparent double alternation in the rat. Psychonomic Science, 1967, 9, 283-284.

Mellgren, R. L., Fouts, R. S., \& Martin, J. W. Approach and escape to conspecific odors of reward and non-reward. Animal Learning \& Behavior, 1973, 1, 129-132.

Prytula, R. E., \& Davis, S. F. The relationship between locus of odor cues and double-alternation responding in the rat. Animal Learning \& Behavior, 1976, 4, 352-356.

Seago, J. D., Ludvigson, H. W., \& Remley, N. R. Effects of anosmia on apparent double-alternation in the rat. Journal of Comparative and Physiological Psychology, 1970, 71, $435-442$.

Sherman, J. E., \& Liebeskind, J. C. An endorphinergic, centrifugal substrate of pain modulation: Recent findings, current concepts and complexities. Proceedings, Association for Research in Nervous and Mental Diseases. New York: Raven Press, 1979.

Terenius, L. Endogenous peptides and analgesia. Annual Review of Pharmacology, 1978, 18, 189.

VOORHEEs, J. W. Single-cell recording in the rat olfactory bulb. Unpublished doctoral dissertation, Texas Christian University, 1980.

(Received for publication September 5, 1981.) 